\title{
Impacto do Reconhecimento de Ativos Fiscais Diferidos na Estrutura Financeira e no Desempenho Econômico de Empresas Brasileiras
}

\section{Impact of Deferred Taxes Assets Recognition in Financial Structure and Economic Performance of Brazilian Companies}

\section{Clóvis Antônio Kronbauer}

Doutor em Contabilidade e Auditoria - Universidad de Sevilla - Espanha

PPG em Ciências Contábeis - Universidade do Vale do Rio dos Sinos - UNISINOS

Endereço: Av. Pedro Américo, no 34 - Apto 301, Bairro São José

CEP: 93.040-120 - São Leopoldo - RS - Brasil

E-mail: clovisk@unisinos.br

Telefone: (51) 3591-1122 R: 1597

\section{Marcos Antônio Souza}

Doutor em Controladoria e Contabilidade - FEA/USP

PPG em Ciências Contábeis - Universidade do Vale do Rio dos Sinos - UNISINOS

Endereço: Av. Unisinos, no950, Bairro Cristo Rei

CEP: 93.022-000 - São Leopoldo - RS - Brasil

E-mail: marcosas@unisinos.br

Telefone: (51) 3591-1122 R: 1580

\section{Fabiano Lima Webber}

Mestre em Ciências Contábeis - Universidade do Vale do Rio dos Sinos -UNISINOS Professor da Faculdade de Ciências Contábeis da Universidade de Passo Fundo - UPF Endereço: Rua João de Césaro, no 255 apto. 801 - Bairro Rodrigues

CEP: 99.070-140- Passo Fundo - RS

E-mail: fabiano@esacon.com.br

Telefone: (54) 9975-2625 ou 54 3313-4534

\section{Ernani Ott}

Doutor em Ciências Econômicas e Empresarias - Universidad de Deusto - Espanha PPG em Ciências Contábeis - Universidade do Vale do Rio dos Sinos - UNISINOS Endereço: Av. Unisinos, no 950, Bairro Cristo Rei

CEP: 93.022-000 - São Leopoldo - RS - Brasil

E-mail: Ernani@unisinos.br

Telefone: (51) 3591-1122 R: 1556

Artigo recebido em 01/03/2012. Revisado por pares em 19/03/2012. Reformulado em 19/04/2012. Recomendado para publicação em 28/05/2012 por Sandra Rolim Ensslin (Editora Científica). Publicado em 28/06/2012. 


\title{
Resumo
}

O trabalho analisa o impacto do reconhecimento de Ativos Fiscais Diferidos (AFDs) na estrutura financeira e no desempenho econômico de 36 empresas integrantes do nível de governança corporativa Novo Mercado da BM\&FBOVESPA, com dados das demonstrações contábeis de 2006 a 2008, e tem abordagem quantitativa-descritiva, sendo documental quanto aos procedimentos técnicos. Constatou-se, pelo Teste " $\mathrm{t}$ ", que o reconhecimento de AFDs tem impacto estatisticamente significativo nos índices de liquidez e endividamento; e, pelo teste de correlação e análise de dependência pela regressão múltipla, os resultados revelaram não existir relação significativa entre o nível de reconhecimento de AFDs e as variáveis explicativas.

Palavras-chave: Ativos fiscais diferidos. Reconhecimento contábil. Desempenho econômico. Posição financeira.

\begin{abstract}
The article aims is to analyze the impact of the deferred tax assets (DFAs) recognition in financial structure and economic performance of 36 companies that are part of new market level of corporate governance the BM\&FBOVESPA, with data from financial statements for the period 2006 to 2008. The study approach is quantitative, and, related to the aims, descriptive; data was collected through documental analysis. It was found through the " $\mathrm{t}$ " test, that the recognition of DFAs has statistically significant impact on liquidity ratios and debt; and, .was applied the correlation test and dependency analysis through multiple regressions. The results reveal no significant relationship between the level of recognition of DFAs and explanatory variables.
\end{abstract}

Keywords: Deferred taxes assets. Recognition accounting. Economic performance.Financial position.

\section{Introdução}

A relação entre a Contabilidade e a legislação tributária tem sido pautada por conflitos no que se refere a critérios de mensuração e contabilização dos eventos contábeis (KRONBAUER; MORENO, 2005). Para os autores, os conflitos ou divergências são originados, principalmente, pela natureza e objetivos da informação gerada pela Contabilidade baseada nos princípios contábeis, que em muitos aspectos são diferentes dos objetivos da legislação tributária.

A principal consequência, de acordo com Hendriksen e Van Breda (1999), é que as diferenças entre os objetivos da normativa tributária e os princípios e normas contábeis resultam em divergências entre o resultado fiscal tributável e o resultado contábil, gerando, assim, uma informação contraditória. No intuito de minimizar essas diferenças, já na década de 1990, organismos como o International Accounting Standards Board - 
IASB e o Financial Accounting Standards Board - FASB produziram normas específicas sobre o tratamento contábil do Imposto sobre Lucros.

\begin{abstract}
Com referência às normativas contábeis brasileiras relacionadas ao tema, cabe apresentar as normas que serviram de base ao período em que se realizou este estudo. Em 1998, a Comissão de Valores Mobiliários (CVM) editou a Deliberação n. 273, aprovando o pronunciamento do Instituto dos Auditores Independentes do Brasil - IBRACON, sobre a Contabilização do Imposto de Renda e da Contribuição Social. Na sequência, o Conselho Federal de Contabilidade (CFC) aprovou a Resolução n. 998/2004, instituindo a Norma Brasileira de Contabilidade - Técnica - NBC-T 19.2 Tributos sobre Lucros. Ambos os documentos possuíam praticamente a mesma estrutura. Como já referido, essas duas normas eram vigentes para o período desta pesquisa.

Atualmente, o tratamento contábil inerente aos tributos sobre os lucros está regulado pelo Pronunciamento n. 32 do CPC - Tributos sobre o Lucro, o qual foi transformado em norma contábil pela Deliberação CVM n. 599/09 e pela Resolução n. 1.189/09 do CFC (NBC TG 32). Cabe ressaltar que essa normativa vigente não se aplicava ao período de realização desta pesquisa.
\end{abstract}

Dentre seus objetivos, as normativas referidas visam tornar transparente, nas demonstrações contábeis, as diferenças temporárias entre o cálculo dos tributos sobre o lucro baseado na legislação fiscal e a despesa desses tributos com base normativa contábil. Dessas diferenças temporárias surgem os tributos diferidos, os quais incluem os Ativos Fiscais Diferidos (AFDs), representados pelos valores dos tributos a recuperar sobre os lucros em exercícios futuros, relacionados com diferenças temporárias dedutíveis, e com prejuízos fiscais compensáveis (PEREIRA, 2007).

Apesar de os tributos diferidos englobarem tanto Ativos quanto Passivos, ou seja, créditos e obrigações de natureza fiscal, o foco do presente estudo é verificar o impacto do reconhecimento de Ativos Fiscais Diferidos (AFDs) em indicadores financeiros e econômicos das empresas. O estudo segue a mesma linha de outras pesquisas realizadas por pesquisadores brasileiros e espanhóis que integram um grupo de pesquisadores que vêm estudando esse tema em empresas brasileiras e espanholas. Cabe referir ainda que, para realizar este estudo, foram tomados como base os indicadores econômicos e financeiros utilizados na pesquisa de Kronbauer e Alves (2008), direcionado ao foco, objetivos e metodologias descritos nos parágrafos que seguem e na seção 3 .

Pesquisas antecedentes realizadas no Brasil e no exterior motivaram este estudo, destacando-se: Gordon e Joss (2004); García-Ayuso e Zamora (2003); Oliveira, Lemes e Almeida (2008); Moreno et al. (2010); e Kronbauer et al. (2010). Esses estudos são comentados e retomados na seção 2.3 do Referencial Teórico.

Nos estudos referidos no parágrafo anterior, foram encontradas evidencias de que o reconhecimento de AFDs mostrou-se mais relevante em empresas com menor lucratividade, maior endividamento e menor liquidez assim como nas maiores empresas. Percebe-se que os gestores dessas empresas estariam utilizando as margens facilitadas pelas normas contábeis, reconhecendo um maior valor de AFDs quando essa situação melhorasse os indicadores financeiros e econômicos das empresas. Com base nessas constatações, justifica-se este estudo, pois, estando comprovado que o reconhecimento de AFDs pode estar associado ao intuito de melhorar indicadores financeiros e econômicos, 
cabe analisar se essa melhora realmente é tão significativa a partir destes reconhecimentos.

Considerando o contexto apresentado e os estudos anteriores realizados, o objetivo deste estudo é analisar o impacto do reconhecimento de Ativos Fiscais Diferidos nos indicadores econômicos e financeiros de empresas. De forma complementar, também é analisado se os diferentes níveis dos AFDs reconhecidos possuem correlação significativa com as variáveis explicativas (índices econômicos e financeiros) utilizadas no estudo.

Os resultados podem trazer importantes contribuições ao tema, pois, se há motivação em usar as margens facilitadas pelas normas contábeis para reconhecer um maior nível de AFDs para melhorar índices financeiros e econômicos, uma vez comprovada estatisticamente essa melhora, estará reforçada a teoria e consequentemente os achados de estudos anteriores.

A partir desta introdução, o estudo contempla outras quatro seções. A primeira delas corresponde à contextualização teórica do tema; a segunda, ao destaque dos principais aspectos metodológicos da pesquisa; a terceira, à apresentação, análise e discussão dos dados e resultados. Por fim, apresenta-se a conclusão do estudo, seguida da lista de referências utilizadas na sua construção.

\section{Referencial Teórico}

\subsection{Contabilidade Tributária e Normas Contábeis Inerentes a Tributos sobre Lucros}

Como um ramo contábil, a Contabilidade Tributária deve evidenciar a situação do patrimônio e o resultado do exercício, de forma clara e precisa, e, de acordo com os conceitos, princípios e normas básicas da Contabilidade. Entretanto, a legislação tributária, não raras vezes, distorce os resultados econômicos para, por imposição legal, adaptá-los à sua exigência e dar-lhes outro valor (resultado fiscal), que pouco tem a ver com o resultado contábil. A legislação do Imposto de Renda, por exemplo, não aceita certas despesas como dedutíveis das receitas para composição do resultado e exige que sejam acrescentadas ao lucro ou prejuízo contábil para, então, tributar esse resultado fiscal encontrado (FABRETTI, 2006).

Nesse contexto de discrepâncias normativas, foram editadas, no Brasil, a Deliberação CVM n. 273/98 e a NBC T 19.2 do CFC, que têm por objetivo regular o tratamento contábil dos tributos sobre lucros, o reconhecimento de ativos fiscais decorrentes de prejuízos, ou créditos fiscais não utilizados, bem como a sua apresentação e divulgação nas demonstrações contábeis. As normas emitidas pela CVM e pelo CFC, conforme enfatizado por Oliveira et al. (2003), visam contribuir para a adaptação dessas regras contábeis às Normas Internacionais de Contabilidade. Cabe referir que essas Normas aplicam-se ao período do presente estudo e que as normativas brasileiras atuais já se encontram completamente harmonizadas com a Norma Internacional de Contabilidade (IAS) n. 12 do IASB.

Outra consideração importante relativa a essas normativas, apresentada por Kronbauer e Moreno (2005), decorre dos aspectos que estão nelas implícitos e que dizem respeito à observância aos Princípios Contábeis e na manutenção das características qualitativas da informação contábil. Nesse sentido, são ressaltados os seguintes aspectos introdutórios das normativas: (a) as entidades devem registrar contabilmente os efeitos fiscais de suas transações e 
outros eventos, no mesmo período contábil em que registrar essas transações e os outros eventos; (b) o AFD, decorrente de diferenças temporárias e de prejuízos fiscais de Imposto de Renda e bases negativas de contribuição social, deve ser reconhecido, total ou parcialmente, desde que a entidade tenha histórico de lucratividade e expectativa de geração de lucros tributáveis futuros, isto é, a empresa somente poderá reconhecer tais ativos quando tiver razoável certeza da sua recuperação ou realização futura, observando o princípio da competência.

No âmbito internacional, está em vigor, desde 1996 (atualizada em 2000), a IAS 12 - Imposto sobre Lucros, emitida pelo International Accounting Standards Board (IASB). De acordo com Deloitte (2006), o objetivo da IAS 12 é prescrever o tratamento contábil a ser dado aos impostos sobre lucros, relacionados com a recuperação ou liquidação no futuro de valores registrados no ativo e/ou no passivo do balanço patrimonial. Conforme já mencionado, o pronunciamento CPC n. 32 é correspondente à norma do IASB referida.

De acordo com a referida IAS 12 (IASB, 2008), se for provável que a recuperação ou liquidação dos ativos (ou passivos) contabilizados der origem a pagamentos fiscais futuros, maiores ou menores em relação aos que se teria se tal recuperação ou liquidação não tivesse consequências fiscais, a norma exige que a empresa reconheça um passivo (ou ativo) pelo imposto diferido, com algumas exceções bastante restritas, como as diferenças permanentes.

\subsection{Tributos Diferidos e Diferenças Temporárias}

Os tributos diferidos, de acordo com Hendriksen e Van Breda (1999), se originam da diferença entre os tributos calculados com base no lucro tributável (fiscal) e no lucro divulgado (contábil), em função de diferenças temporárias, resultantes de: (a) diferenças quanto ao momento em que ocorrem débitos e créditos ao lucro, também denominadas "diferenças entre períodos"; e (b) diferenças resultantes de bases alternativas de mensuração utilizadas na Contabilidade Financeira e na Contabilidade Fiscal, também denominadas "diferenças de avaliação". Para essas diferenças temporárias, o registro de uma despesa de imposto (ou efeito equivalente sobre o lucro), com base no lucro divulgado antes do imposto, exige uma alocação entre períodos. $\mathrm{O}$ lucro tributável no período corrente, mas reconhecido ou divulgado num período posterior, requer um diferimento de despesa de imposto; o lucro reconhecido para fins contábeis e divulgado no período corrente, mas tributável em período futuro, requer a criação de uma despesa de imposto a pagar.

Portanto, quando existir um lucro tributável no período corrente, que será reconhecido ou divulgado no próximo exercício, forma-se um AFD, o que é denominado por Hendriksen e Van Breda (1999) como diferimento de despesas com imposto. Em contrapartida, quando o lucro tributável no próximo exercício for reconhecido ou divulgado no exercício corrente, formar-se-á uma despesa de imposto a pagar ou um Passivo Fiscal Diferido.

Ainda com respeito às Diferenças Temporárias, Hendriksen e Van Breda (1999, p. 429) mencionam que

é mais fácil exemplificar do que explicar as diferenças temporárias. Consideremos uma situação em que o lucro divulgado por uma empresa, antes do imposto é \$100.000. Supondo uma alíquota de 34\%, uma despesa de imposto de $\$ 34.000$ será divulgada. Incluídas nas vendas realizadas durante o ano há transações que não seriam divulgadas para fins tributários até o exercício seguinte. Por exemplo, a empresa poderia usar a Contabilidade por competência para divulgação financeira e o regime de caixa para fins de imposto. O lucro tributável, portanto, poderia ser de 
apenas $\$ 20.000$, do qual o resultado seria um passivo tributário de apenas $\$$ 6.800. Ou seja: Despesa de imposto $=34 \%$ de $\$ 100.000=\$ 34.000$; Imposto devido $=34 \%$ de $20.000=\$ 6.800$.

A diferença entre esses dois valores é levada para uma conta passiva de impostos diferidos, de $\$ 27.200$. Em outras palavras, a empresa deve \$ 6.800 em impostos agora e, com outros fatores mantidos constantes, deve mais \$27.200 no futuro (quando o lucro se realizar), em virtude da diferença entre a norma contábil e a norma fiscal, a qual permite que, nesse exemplo, o imposto possa ser calculado com base na apuração do lucro pelo regime de caixa. Evidentemente, o contrário também pode ocorrer.

Para Kronbauer e Moreno (2005), as diferenças temporárias, no balanço, ocorrem entre a base fiscal de um ativo ou passivo (valor atribuído para efeitos fiscais) e seu valor contábil dentro do balanço. Esse entendimento corrobora Hendriksen e Van Breda (1999), para os quais as diferenças temporárias constituem o núcleo da teoria contábil a respeito da contabilização do Imposto de Renda, pois os contadores controlam como essas diferenças são tratadas, representando uma causa importante da defasagem entre lucro tributável e lucro divulgado em dado exercício.

As diferenças temporárias, geradoras de passivos ou ativos diferidos, dividem-se em tributáveis e dedutíveis. As diferenças temporárias tributáveis, segundo Iudícibus et al. (2010), dão origem às obrigações fiscais diferidas pois, segundo o regime de competência, o passivo já existe, sendo apenas postergado seu pagamento para período(s) posterior(es). Fernández, Martínes e Álvarez (2003) mencionam que as diferenças temporárias tributáveis dão origem aos valores tributáveis quando determinam o lucro ou prejuízo fiscal relativo a exercícios futuros, isto é, quando o valor contábil do ativo seja recuperado ou o passivo seja exigido. Assim, são nessas situações que há necessidade de compensação do ativo fiscal ou o pagamento do passivo fiscal.

Com relação às diferenças temporárias tributáveis, a Deliberação da CVM n. 273/98 e a NBC-T 19.2 estabelecem que elas surgem quando se inclui receita ou despesa no resultado contábil antes dos tributos sobre o lucro em um exercício e no resultado tributável (base de cálculo do IR) em exercício diferente.

Exemplos de diferenças temporárias tributáveis constam das normas referidas no parágrafo anterior. Um deles é quando o valor do custo ou despesa de depreciação considerada na determinação do resultado tributável for diferente daquele considerado na determinação do resultado contábil, surgindo daí uma diferença entre o valor líquido contábil do ativo e sua base fiscal. Se essa diferença se reverter ao longo do tempo, surge uma diferença temporária. Assim, também da depreciação acelerada para fins fiscais resulta em uma obrigação fiscal diferida, enquanto que uma aceleração da depreciação para fins contábeis resulta em um ativo fiscal diferido.

A IAS 12 (IASB, 2008), ao tratar dessas questões, estabelece que as diferenças temporárias tributáveis são produzidas entre o valor contábil líquido e o valor fiscal líquido de um ativo ou passivo e que num futuro resultarão em valores tributáveis para fins do Imposto sobre Lucros. As seguintes diferenças temporárias tributáveis são apresentadas pela IAS 12 como exemplos de eventos que resultam em obrigações fiscais diferidas quando (a) a depreciação considerada para efeitos fiscais for superior à reconhecida contabilmente, o que ocorre nos casos de depreciação acelerada ou mesmo em operações de arrendamento financeiro; (b) nos processos de fusão e aquisição aparece uma diferença temporária tributável, dando origem a um passivo por impostos diferidos, quando o valor contábil de um

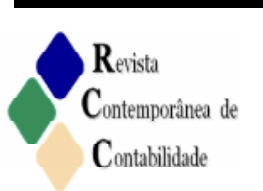


ativo é incrementado até o seu valor de mercado. As combinações de negócios possuem um tópico específico na referida norma do IASB.

A segunda classe de diferenças temporárias, as Dedutíveis, também são tratadas nas normativas em questão. Essa classe de diferenças temporárias refere-se a situações em que, mesmo que contabilmente já esteja reconhecido o custo ou despesa no mês ou exercício, sua dedutibilidade para fins de Tributos sobre o Lucro só ocorrerá em períodos posteriores. Fernández, Martínes e Álvarez (2003) ressaltam que essas diferenças originam valores dedutíveis no momento em que se determina o lucro ou prejuízo fiscal correspondente a exercícios seguintes, quando efetivamente o valor contábil do ativo seja recuperado e o passivo liquidado. Iudícibus et al. (2010) esclarecem que nessas situações haverá o tributo sobre o lucro pago ou a pagar, mas a despesa relativa a ele só poderá ser apropriada em um período posterior. Se a despesa contabilizada no exercício não é dedutível, faz-se necessário reconhecer na despesa por tributos sobre o lucro a redução relativa a ela, surgindo, assim, um Ativo Fiscal Diferido, ou seja, um tributo antecipado.

Com relação às diferenças temporárias dedutíveis, Iudícibus et al., (2010) esclarecem que estas resultarão em valores a serem deduzidos no cálculo do resultado tributável de períodos futuros, quando o valor contábil do ativo ou passivo for recuperado ou liquidado. Os exemplos apresentados são os seguintes:

1. Provisões: (a) para garantia de produtos, contabilizadas no período de sua venda, mas dedutíveis para fins fiscais somente quando realizadas; (b) para gastos com manutenção e reparo de equipamentos, dedutíveis para fins fiscais, apenas quando estes forem efetivamente realizados; (c) para riscos fiscais e outros passivos contingentes; (d) contabilizadas acima dos limites permitidos pela legislação fiscal, cujos excessos sejam recuperáveis fiscalmente no futuro; (e) para perdas permanentes em investimentos.

2. Receitas tributadas em determinado período, que pelo Regime da Competência somente serão reconhecidas contabilmente em período ou períodos futuros.

3. Amortização contábil de ágio, que somente será dedutível por ocasião de sua realização por alienação ou baixa.

4. Certos ativos podem ser reavaliados sem que se faça um ajuste equivalente para fins tributários. A diferença temporária dedutível surge se a base fiscal do ativo exceder o seu valor contábil ajustado ao valor de mercado (reavaliação negativa), ou valor de recuperação.

De acordo com a IAS 12 (IASB, 2008), as diferenças temporárias dedutíveis são aquelas entre o valor contábil e fiscal de um ativo ou passivo, que resultarão em valores a serem deduzidos no cálculo do resultado tributável de períodos futuros. São exemplos de diferenças temporárias dedutíveis, entre outros:

1. As provisões para pensões podem ser deduzidas para determinar o resultado contábil, mas não serão dedutíveis até o momento em que a empresa pague aos funcionários os valores provisionados, ou faça os respectivos aportes a um fundo externo que administre estes recursos. Nesta situação, há uma diferença temporária dedutível entre o valor contábil líquido do passivo e sua base fiscal, que normalmente terá valor zero, gerando, assim, um ativo por impostos diferidos, o qual se vai reconhecendo à medida que as provisões são dotadas; sua reversão somente ocorrerá quando são pagas as pensões ou realizados os aportes ao fundo externo; 
2. Numa fusão de negócios (fusão de compra ou aquisição), o custo da compra se distribuirá entre os ativos e passivos reconhecidos, tomando como base os valores de mercado (valor justo) destes elementos no momento de realizar a transação. Quando se reconhece um passivo cujos custos associados não se configurem como gasto fiscal até exercícios posteriores, aparecerá uma diferença temporária dedutível, originando um ativo por impostos diferidos.

Para fins de reconhecimento do Ativo Fiscal Diferido, a Deliberação da CVM n. 273/98, a NBC-T 19.2 do CFC e a Instrução CVM n. 371/ 2002, em seu art. $2^{\circ}$, estabelecem que a companhia deverá atender, cumulativamente, a uma série de condições, destacando-se apresentar um histórico de rentabilidade e expectativa de geração de lucros tributáveis no futuro.

Kronbauer e Moreno (2005) compararam as normas brasileiras com a norma internacional para a contabilização sobre o lucro, constatando haver compatibilidade entre ambas. Isso decorre do fato de que as normas brasileiras tiveram a sua elaboração baseada na IAS 12, o que é confirmado por Oliveira et al. (2003) que ressaltam que o IBRACON, autor da norma aprovada pela Deliberação CVM n. 273/98, tem uma grande preocupação em contribuir para a adaptação das metodologias adotadas no Brasil às Normas Internacionais de Contabilidade.

\subsection{Ativos Fiscais Diferidos (AFDs) e os Efeitos de seu Reconhecimento}

Os AFDs são a ponte entre certos eventos registrados extracontabilmente e o balanço patrimonial. Para Wasserman (2004), eles representam um benefício fiscal futuro, montante do qual provavelmente será reduzido o valor do Imposto de Renda.

Segundo Fernández, Martínes e Álvares (2003), esses ativos surgem das diferenças temporárias dedutíveis e dos prejuízos fiscais compensáveis em períodos futuros. Para Wasserman (2004), o AFD também pode ser entendido como o benefício fiscal trazido para o corpo das demonstrações contábeis de eventos extracontábeis (reversão das diferenças temporárias e compensação de prejuízo fiscal) que reduzirão o Imposto de Renda a pagar ou pago.

Pereira (2007) destaca que o IBRACON, por meio da Norma e Procedimento Contábil - NPC n. 25/98, conceitua AFD como valores do Imposto de Renda e da contribuição social a recuperar em períodos futuros, com relação a diferenças temporárias dedutíveis e compensação futura de prejuízos fiscais não utilizados. Trata-se de valores dos tributos a recuperar em exercícios futuros sobre os lucros, com relação a diferenças temporárias dedutíveis e compensação de prejuízos fiscais. Pereira acrescenta que o AFD pode se originar das diferenças temporárias de dedutibilidade entre o lucro tributável e o lucro contábil. Outra fonte é o prejuízo fiscal e a base negativa de contribuição social. Nesse caso, o ativo fiscal diferido representará a economia tributária decorrente da redução da base de cálculo do imposto, em virtude do abatimento de prejuízo fiscal.

Com relação aos efeitos e motivações para o reconhecimento de Ativos Fiscais Diferidos (AFDs), cabe retomar estudos anteriores que tratam do tema e que são a base teórico-empírica para esta investigação.

Para Gordon e Joss (2004), a decisão de reconhecer Ativos Fiscais Diferidos pode estar relacionada com a busca na redução no índice de endividamento da empresa, em função do aumento do valor de seu ativo e do consequente aumento do valor do patrimônio líquido.

Em estudo de García-Ayuso e Zamora (2003), observou-se que o reconhecimento de Ativos Fiscais Diferidos está relacionado com o nível de lucros passados e futuros das

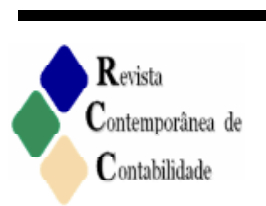


empresas, o que caracterizaria uma prática de normalização de lucros. A possível melhora dos índices de endividamento, em decorrência do reconhecimento desses créditos fiscais, também mostrou-se como fator determinante na decisão de reconhecer esses ativos.

Kronbauer (2008) examinou as informações relativas à divulgação dos AFDs em empresas do IBOVESPA e do IBEX-35, concluindo que, em ambos os casos, a divulgação é semelhante. Concluiu que nas empresas da amostra IBOVESPA, no período de 2003 a 2005, os índices que poderiam estar influenciados eram o Endividamento e o Tamanho da Empresa (ativo total). Já na amostra IBEX-35, o mesmo ocorreu com a Rentabilidade sobre o Patrimônio Líquido e o Tamanho da Empresa (receita líquida anual). Os resultados sugerem indícios de gerenciamento de resultados nas empresas, apesar de todas estarem cumprindo com as normas contábeis.

Oliveira, Lemes e Almeida (2008) num estudo de caso múltiplo realizado em empresas do setor de telecomunicações, concluíram que o reconhecimento de AFDs possibilitou, entre outras coisas, o aumento do lucro passível de distribuição para os acionistas, bem como os dividendos propostos sobre esses lucros. Os autores observaram também que algumas empresas mantiveram estáveis seus níveis de lucratividade e que o reconhecimento de ativos fiscais pode ter auxiliado nessa situação.

De acordo com Moreno et al., (2010), em pesquisa com uma amostra de companhias espanholas, percebem-se evidências de que as empresas com maior endividamento reconheceram um maior valor de diferenças temporárias positivas. Esse comportamento também foi observado em empresas de menor liquidez, o que permite inferir que o reconhecimento dos ativos resultantes de tais diferenças temporárias melhorou a situação de liquidez e endividamento das empresas.

Em estudo realizado por Kronbauer et al., (2010), observou-se que o reconhecimento de Ativos Fiscais Diferidos é recorrente ao longo do período analisado, e a variabilidade desse reconhecimento se repete, ou seja, empresas que têm elevados valores de AFDs reconhecidos evidenciaram essa prática durante todo o período analisado. Também observou-se neste estudo que: a) empresas com maior Endividamento (ENDTO) tendem a reconhecer maior valor de AFDs; b) empresas com menor Rentabilidade tendem a reconhecer maior valor de AFDs; e c) empresas com menor Liquidez Geral (LG) tendem a reconhecer maior valor de AFDs. Percebe-se assim que, intencionalmente ou não, a decisão de reconhecer AFDs impactaria positivamente nos indicadores financeiros e econômicos das empresas.

\subsection{Evidenciação Contábil e Reconhecimento de AFDs}

Gonçalves e Ott (2002) assinalam que um dos importantes papéis da Contabilidade é prestar informações aos seus usuários (acionistas, administradores, credores, fornecedores, clientes, empregados, governo, sociedade, etc.). Para os autores, associado à informação está o termo Evidenciação Contábil (disclosure).

Pricewaterhousecoopers (1997) assinala que disclosure diz respeito ao meio pelo qual a administração de cada entidade atende, de forma transparente, aos seus usuários externos. Esse atendimento está relacionado a disponibilizar informações corretas e necessárias para a tomada de decisões, as quais podem abranger desde a situação patrimonial e financeira da entidade até sua lucratividade, origens e aplicações de recursos em determinado período. Com esse mesmo sentido, posiciona-se o IBGC (2009), 
assumindo que a transparência sugere que a administração deva cultivar o desejo de informar, e não apenas fazê-lo por obrigação, uma vez que a boa comunicação interna e externa, quando espontânea, franca e rápida, resulta num clima de confiança, tanto no âmbito interno da empresa quanto nas suas relações com terceiros.

Essa comunicação com o mercado não se deve restringir unicamente ao desempenho econômico-financeiro, mas deve contemplar também os demais elementos (inclusive intangíveis) que norteiam a ação empresarial e que conduzem à criação de valor (IBGC, 2009). Com base em tal afirmação, pode-se inferir que disclosure possui um sentido amplo, pois cada empresa deverá divulgar toda e qualquer informação que possa ser útil ao interessado externo e que possa conduzi-lo à melhor avaliação possível da entidade.

Dantas et al., (2005) argumentam que existe uma similaridade entre a abrangência do disclosure e a definição de transparência, salientando que não há apenas o sentido de divulgar, mas fazê-lo com qualidade, oportunidade e clareza. Segundo os autores, para que se alcance a transparência pretendida com o disclosure, torna-se necessária a divulgação de informações qualitativas e quantitativas que possibilitem aos usuários formar uma compreensão das atividades desenvolvidas e dos seus riscos, observando também os critérios de tempestividade, detalhamento e relevância necessários.

Cumpre ressaltar, diante do entendimento dos autores citados, que a correta divulgação dos efeitos fiscais das transações realizadas pelas empresas fazem parte das boas práticas de disclosure requeridas pelos usuários das informações contábeis.

\section{Procedimentos Metodológicos}

\subsection{População e Amostra}

A população utilizada neste estudo é composta pelas 99 empresas que faziam parte do nível de Governança Corporativa Novo Mercado da BM\&FBOVESPA ao final do exercício de 2008. A escolha das empresas do novo mercado deu-se em função das exigências de transparência de disclosure, a que elas estão submetidas pela BM\&FBOVESPA, o que pode sugerir, também, a adoção de normas contábeis com maior correção e menos viesada.

Para compor a amostra foram excluídas inicialmente da população 63 empresas, pois parte delas se dedica a atividades financeiras e possuem tratamento contábil específico, seguindo regulamentações do Banco Central do Brasil. Além delas, também foi excluída a parte que é formada por controladoras, as quais não se dedicam a atividades comercial, industrial e de prestação de serviços. Outras empresas foram excluídas por não haver publicação de suas demonstrações contábeis em todos os exercícios pesquisados ou por ter sido observada alguma deficiência nas demonstrações publicadas, o que poderia comprometer os resultados da pesquisa. Por fim, restou uma amostra não probabilística e intencional constituída por 36 empresas.

Para fazer parte da amostra final, além divulgar as demonstrações contábeis nos três exercícios (de 2006 a 2008), as empresas deveriam, também, possuir registro de Ativo Fiscal Diferido, ou alguma conta que se referisse a tributos (sobre lucros) diferidos. Nesse caso, o critério para aceite ou não das empresas que não possuíam a rubrica de Ativo Fiscal Diferido era a utilização dos termos Diferido ou Diferidos em alguma conta relacionada a tributos, no caso, Imposto de Renda ou Contribuição Social.

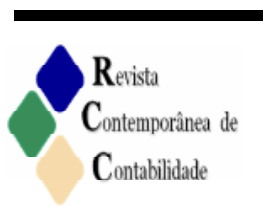




\subsection{Coleta e Tratamento dos Dados}

Os dados foram obtidos no site da BM\&FBOVESPA, em relatórios anuais das empresas, para se calcularem os índices econômico-financeiros utilizados no estudo, os quais podem ser influenciados pela existência de AFDs. Os índices foram calculados considerando: (a) reconhecimento de AFDs; (b) não reconhecimento de AFDs.

Cabe referir que, para a realização das análises, optou-se por excluir o valor dos AFDs reconhecidos no Ativo, ou seja, para a comparação deduziu-se esse valor do numerador. Não foi deduzido o cálculo de Passivos Fiscais do Denominador, quando liquidez e endividamento pelos seguintes aspectos:

a) Era objetivo observar o real impacto dos AFDs no Ativo (Circulante, Realizável ou Total).

b) O fato de haver AFDs reconhecidos pela empresa, não implica que haja, de forma concomitante, Passivos Fiscais Diferidos reconhecidos.

c) Entende-se que essa mútua exclusão ou compensação seria um estudo distinto, que pode ser realizado no futuro.

Os resultados obtidos com os cálculos dos índices ( $\mathrm{a}$ e b) foram comparados entre si para verificar se o reconhecimento de AFDs interfere na situação econômica e financeira das empresas da amostra. Após, foram efetuados testes estatísticos de diferenças de médias, verificando-se se as alterações nos índices calculados foram significativas ou não.

Por fim, realizou-se análise de correlação, visando verificar se o nível de reconhecimento de AFDs possui relação significativa com variáveis inerentes à situação financeira e econômica das empresas estudadas. Para tanto, foram calculados os coeficientes de correlação de Pearson entre as variáveis analisadas.

\subsection{Análise dos Dados}

Para analisar os dados, primeiro (seção 4.1) se considerou sobre a não normalidade dos dados e a verificação de outliers. Na sequência, na seção 4.2, são apresentados os cálculos das médias dos índices econômico-financeiros. Para verificar se o reconhecimento de AFDs altera significativamente os índices econômico-financeiros, utilizou-se o Teste "t" para amostras pareadas, visando testar as hipóteses de igualdade entre as médias dos índices sem o reconhecimento e com o reconhecimento de AFDs. Por exemplo, comparou-se a média dos índices de Liquidez Corrente sem AFDs com a média dos índices de Liquidez Corrente com AFDs, procedimento que se repete com os demais índices.

Uma limitação do estudo é a não realização de testes de variâncias antes, como procedimento que antecede à realização dos testes de diferenças de médias.

Cada categoria de índices foi calculada para cada empresa, nos três períodos analisados, de acordo com os seguintes critérios:

- LC - Liquidez Corrente: obtida pela divisão do valor do Ativo Circulante pelo valor do Passivo Circulante.

- LG - Liquidez Geral: obtida a partir da divisão entre os valores (Ativo Circulante + Realizável a Longo Prazo) pelo valor do Exigível Total (Circulante e a Longo Prazo).

- ENDTO - Endividamento obtido pela divisão entre Exigível Total e Ativo Total. 
- RPL - Rentabilidade sobre o Patrimônio Líquido: resultante da divisão entre o valor do Lucro Líquido e o valor do Patrimônio Líquido Médio. Utilizou-se o PL médio nesse cálculo, pois os resultados vão sendo auferidos ao longo do exercício e reinvestidos na atividade de forma automática. Assim sendo, reduz-se o risco de superdimensionar ou subdimensionar e retorno sobre o PL.

\section{Análise e Interpretação dos Dados}

\subsection{Análise de Distribuição dos Dados e Outliers}

Pelo tamanho da amostra, a não normalidade na distribuição dos dados tende a não afetar os resultados. Isso se constata pelo Teorema do Limite Central, o qual descreve que, quanto maior a amostra, maior a probabilidade de distribuição normal, ou seja, a distribuição amostral pode ser aproximada por uma distribuição normal de probabilidade sempre que o tamanho da amostra é igual ou superior a trinta indivíduos (ANDERSON; SWEENEY; WILLIAMS, 2003). Os autores mencionam ainda que, se o tamanho da amostra é maior ou igual a 30, não há necessidade de a população ter uma distribuição normal, porém, se a amostra for menor que isso, a população precisa ter uma distribuição normal ou aproximadamente normal. Assim, é irrelevante comprovar a normalidade dos dados.

Por meio do teste de "Grubb", buscou-se identificar os outliers que são contados da seguinte forma: dado "I" (intervalo interquartil=Q3-Q1), quaisquer valores $<=\mathrm{Q} 1-1.5 \mathrm{I}$ ou $>=\mathrm{Q} 3+1.5 \mathrm{I}$ podem ser outliers "moderados"; quaisquer valores $<=\mathrm{Q} 1-3 \mathrm{I}$ ou $>=\mathrm{Q} 3+3 \mathrm{I}$ podem ser outliers "extremos".

A partir desse teste, observou-se que as variáveis LC com AFDs, LG com AFDs, RPL com AFDs e IAFD possuem outliers. Apesar de terem sido identificados outliers moderados e extremos no conjunto das variáveis analisadas, a simulação revelou que estes não afetam significativamente os resultados, bem como se espera que se tenham sempre empresas que não sejam semelhantes, garantindo que a pesquisa seja mais fidedigna à amostra selecionada.

Concluído o exame preliminar dos dados da amostra e considerando que estes não apresentam fator que impeça sua utilização para o estudo, apresenta-se a análise dos impactos do reconhecimento dos Ativos Fiscais Diferidos na situação financeira e econômica das empresas.

\subsection{Impacto Econômico e Financeiro do Reconhecimento de AFDs}

\subsubsection{Análise do Comportamento do Índice de Liquidez Corrente (LC)}

A estatística descritiva relativa aos índices de liquidez corrente sem e com o reconhecimento de AFDs, nos anos de 2006, 2007 e 2008, está apresentada na Tabela 1.

Tabela 1 - Índices de Liquidez Corrente sem e com o reconhecimento de AFDs

\begin{tabular}{ccccccccc}
\hline Índices & ANO & Média & Desv. Padrão & Variância & $\mathbf{1}^{\mathbf{0}}$ Quartil & Mediana & $\mathbf{3}^{\mathbf{0}}$ Quartil & $\mathbf{n}$ \\
\hline \multirow{2}{*}{ LC Sem } & $\mathbf{2 0 0 6}$ & 2,8167 & 4,8359 & 23,3865 & 0,9903 & 1,4217 & 2,8718 & 34 \\
AFDs & $\mathbf{2 0 0 7}$ & 2,6510 & 1,9135 & 3,6617 & 0,3977 & 2,6335 & 3,6528 & 35 \\
& $\mathbf{2 0 0 8}$ & 2,3490 & 1,6666 & 2,7777 & 0,3925 & 2,0634 & 2,8568 & 36 \\
\hline
\end{tabular}


Impacto do Reconhecimento de Ativos Fiscais Diferidos na Estrutura Financeira e no Desempenho Econômico...

\begin{tabular}{ccccccccc}
\hline & & & & & & & \\
\hline LC Com & $\mathbf{2 0 0 6}$ & 2,8401 & 4,8359 & 23,3862 & 0,9903 & 1,4257 & 2,9714 & 34 \\
AFDs & $\mathbf{2 0 0 7}$ & 2,6755 & 1,9267 & 3,7123 & 1,1181 & 2,6343 & 3,7485 & 35 \\
& $\mathbf{2 0 0 8}$ & 2,3778 & 1,6714 & 2,7937 & 1,1585 & 2,0907 & 2,8908 & 36 \\
\hline
\end{tabular}

Fonte: Dados da pesquisa.

No ano de 2006, tem-se um "n" de 34 empresas, pois duas empresas não apresentavam valores relativos a AFDs nesse período; em 2007, somente uma empresa não possuía AFDs; e, em 2008, todas as empresas possuíam valores reconhecidos nas contas relativas a Ativos Fiscais Diferidos.

Na Tabela 1, observa-se que a média dos índices de liquidez corrente aumenta com o reconhecimento de AFDs, fato observado nos três anos examinados. O índice médio de Liquidez Corrente (LC) sem AFDs no ano de 2006 é 2,8167; o mesmo índice, com o valor dos AFDs somado ao Ativo Circulante no mesmo ano, passa para 2,8401. Em 2007, o índice sem AFDs é 2,651; e, com AFDs, passa para 2,675. Já em 2008, o índice médio de LC sem AFDs é 2,349, passando para 2,377 quando considerados no Ativo Circulante o valor dos AFDs.

Mesmo que seja óbvio que o valor dos AFDs aumenta o indicador de liquidez, cabe analisar se essa interferência é significativa. Para tanto, aplicou-se o Teste " $t$ " para amostras pareadas para verificar se existe diferença estatisticamente significante entre as médias do índice de liquidez corrente sem o reconhecimento de AFDs e com o reconhecimento de AFDs, conforme Tabela 2.

Tabela 2 - Significância entre a diferença de LC sem e com o reconhecimento de AFDs

\begin{tabular}{cccc}
\hline Índice & ANO & t-estatístico & P-Valor \\
\hline \multirow{2}{*}{ LC } & $\mathbf{2 0 0 6}$ & $-2,342$ & 0,025 \\
& $\mathbf{2 0 0 7}$ & $-4,060$ & 0,000 \\
& $\mathbf{2 0 0 8}$ & $-5,521$ & 0,000 \\
\hline
\end{tabular}

Fonte: Dados da pesquisa.

Observa-se, na Tabela 2, que em todos os anos a diferença entre as médias de liquidez corrente sem e com AFDs é estatisticamente significante em um nível de confiança de $95 \%$. Assim, entende-se que esse índice, em média, é estatisticamente diferente sem o reconhecimento de AFDs e com o reconhecimento de AFDs, ou seja, o reconhecimento dos AFDs aumenta a liquidez corrente das empresas da amostra em níveis estatisticamente significantes.

Nesse caso, seria lógico que os responsáveis pela elaboração das demonstrações contábeis revelassem maior propensão em reconhecer AFDs, pois isso poderia melhorar significativamente os índices de liquidez das empresas. Observam-se evidências que corroboram com resultados de estudos anteriores referidos no item 2.3 desta pesquisa.

\subsubsection{Análise do Comportamento do Índice de Liquidez Geral (LG)}

Na Tabela 3, apresenta-se a estatística descritiva dos índices médios de Liquidez Geral (LG) calculados sem e com o reconhecimento de AFDs, no período estudado. 
Clóvis Antônio Kronbauer, Marcos Antônio Souza, Fabiano Lima Webber e Ernani Ott

Tabela 3 - Índices de Liquidez Geral sem e com o reconhecimento de AFDs

\begin{tabular}{ccccccccc}
\hline Índices & ANO & Média & Desvio Padrão & Variância & $\mathbf{1}^{\mathbf{0}}$ Quartil & Mediana & $\mathbf{3}^{\mathbf{0}}$ Quartil & $\mathbf{n}$ \\
\hline LG Sem & $\mathbf{2 0 0 6}$ & 1,6594 & 2,9133 & 8,4871 & 0,7438 & 1,0336 & 1,2954 & 34 \\
AFDs & $\mathbf{2 0 0 7}$ & 1,5757 & 1,1808 & 1,3944 & 0,6330 & 1,1720 & 2,3396 & 35 \\
& $\mathbf{2 0 0 8}$ & 1,2684 & 0,9605 & 0,9225 & 0,6727 & 1,0383 & 1,3908 & 36 \\
& $\mathbf{2 0 0 6}$ & 1,7405 & 2,9503 & 8,7046 & 0,7889 & 1,0860 & 1,3119 & 34 \\
LG Com & $\mathbf{2 0 0 7}$ & 1,6621 & 1,2461 & 1,5528 & 0,6669 & 1,2322 & 2,3486 & 35 \\
AFDs & $\mathbf{2 0 0 8}$ & 1,3612 & 1,0597 & 1,1229 & 0,7281 & 1,0979 & 1,5415 & 36 \\
\hline
\end{tabular}

Fonte: Dados da pesquisa.

Identifica-se, na Tabela 3, que os índices de LG sofrem alterações semelhantes àquelas identificadas nos índices de LC, ou seja, houve melhora nos índices de Liquidez Geral (LG) com o reconhecimento de Ativos Fiscais Diferidos por parte das empresas.

A média do Índice de Liquidez Geral aumenta com o reconhecimento de AFDs, fato observado nos três anos examinados. $\mathrm{O}$ índice médio de Liquidez Geral (LG) sem AFDs no ano de 2006 é 1,6593; o mesmo índice, com o valor dos AFDs somados ao Ativo no mesmo ano, passa para 1,7404. Em 2007, o índice sem os AFDs é 1,5756; e, com os AFDs, passa para 1,6621. Já em 2008, o índice médio de LG sem AFDs é de 1,2683, o qual passa para 1,3611 quando considerados no Ativo os valores dos AFDs. O desvio-padrão e a variância referentes a 2006 também são bastante elevados, em razão de a empresa Cia Providência ter uma Liquidez Corrente bem superior às demais.

Nos três anos analisados, a diferença é estatisticamente significativa, num intervalo de confiança de $95 \%$, ou seja, a média dos índices de Liquidez Geral sem o reconhecimento de AFDs é estatisticamente diferente da média dos índices de Liquidez Geral com o reconhecimento de AFDs. A média do índice de Liquidez Geral em 2006 passa de 1,6593 para 1,7404 , um aumento de $5 \%$, o que é estatisticamente significante com $99 \%$ de confiança. Percebe-se que a Liquidez Geral também aumenta com o reconhecimento de AFDs em níveis estatisticamente significantes. Estas afirmações se confirmam na Tabela 4.

Tabela 4 - Significância entre a diferença de LG sem e com o reconhecimento de AFDs

\begin{tabular}{cccc}
\hline Índice & ANO & t-estatístico & P-Valor \\
\hline \multirow{2}{*}{ LG } & $\mathbf{2 0 0 6}$ & $-3,768$ & 0,000 \\
& $\mathbf{2 0 0 7}$ & $-3,781$ & 0,001 \\
& $\mathbf{2 0 0 8}$ & $-3,815$ & 0,001 \\
\hline
\end{tabular}

Fonte: Dados da pesquisa.

No que se refere à Liquidez Geral, confirma-se a mesma situação já observada em relação à liquidez corrente, ou seja, os responsáveis pela elaboração das demonstrações contábeis podem ter maior propensão em reconhecer AFD, quando este melhora significativamente os índices de liquidez de suas empresas, melhorando assim a posição financeira perante os usuários das informações contábeis.

\subsubsection{Análise do Comportamento do Índice de Endividamento (ENDTO)}

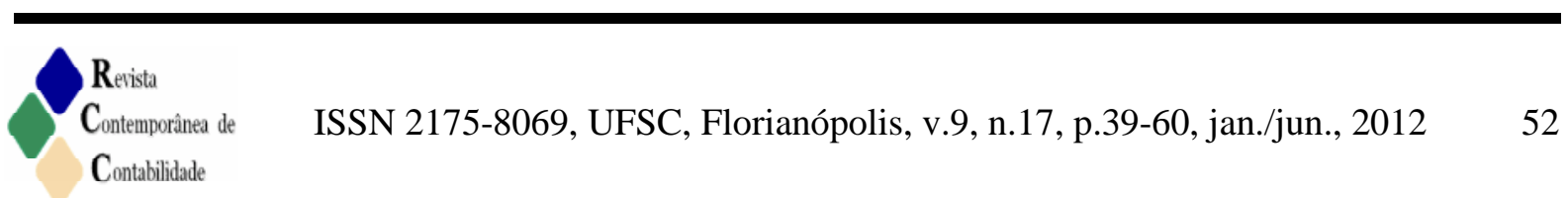


Observando os dados da Tabela 5, constata-se que a média do Índice de Endividamento diminui com o reconhecimento de AFDs, fato observado nos três anos examinados.

Tabela 5 - Índices de Endividamento sem e com o reconhecimento de AFDs

\begin{tabular}{ccccccccc}
\hline Índices & ANO & Média & Desvio Padrão & Variância & $\mathbf{1}^{\mathbf{0}}$ Quartil & Mediana & $\mathbf{3}^{\mathbf{0}}$ Quartil & $\mathbf{n}$ \\
\hline \multirow{3}{*}{ Endto. Sem AFDs } & $\mathbf{2 0 0 6}$ & 0,5368 & 0,2124 & 0,04514 & 0,4058 & 0,5247 & 0,6274 & 34 \\
& $\mathbf{2 0 0 7}$ & 0,4509 & 0,2048 & 0,04194 & 0,2614 & 0,4334 & 0,5911 & 35 \\
& $\mathbf{2 0 0 8}$ & 0,5028 & 0,2234 & 0,0499 & 0,3442 & 0,4731 & 0,6177 & 36 \\
Endto. Com AFDs & $\mathbf{2 0 0 6}$ & 0,5202 & 0,2056 & 0,0423 & 0,3947 & 0,5062 & 0,62307 & 34 \\
& $\mathbf{2 0 0 7}$ & 0,4391 & 0,2008 & 0,0403 & 0,2479 & 0,4294 & 0,5759 & 35 \\
\hline & $\mathbf{2 0 0 8}$ & 0,4851 & 0,2143 & 0,0459 & 0,3415 & 0,4604 & 0,5899 & 36 \\
\hline
\end{tabular}

Fonte: Dados da pesquisa.

O índice médio de Endividamento sem AFDs no ano de 2006 é 0,5368; o mesmo índice, mas com o valor dos AFDs somado ao Ativo no mesmo ano, passa para 0,5201. Em 2007, o índice sem os AFDs é 0,4509; e, com os AFDs, passa para 0,4391. Já em 2008, o índice médio de Endto sem AFDs é 0,5028, diminuindo para 0,4850 quando considerados no Ativo o valor dos AFDs.

O resultado do Teste "t", apresentado na Tabela 6 , revela que existe uma diferença estatisticamente significante entre as médias do Índice de Endividamento sem e com o reconhecimento de AFDs em todos os anos, com um grau de confiança de $95 \%$.

Desse modo, percebe-se que o reconhecimento de AFDs por parte das empresas da amostra reflete-se positivamente nas suas demonstrações contábeis, fazendo com que haja uma diminuição estatisticamente significante do Índice de Endividamento das empresas.

Tabela 6 - Significância entre a diferença de Endividamento sem e com o reconhecimento de AFDs

\begin{tabular}{cccc}
\hline Índice & ANO & t-estatístico & P-Valor \\
\hline \multirow{3}{*}{ Endividamento } & 2006 & 3,656 & 0,000 \\
& 2007 & 4,109 & 0,000 \\
& 2008 & 5,167 & 0,000 \\
\hline
\end{tabular}

Fonte: Dados da pesquisa.

Esses resultados também corroboram constatações de estudos anteriores referidos na seção 2.3, pois, se o reconhecimento de AFDs possibilita diminuir significativamente os índices de endividamento, seria lógico que os responsáveis pelas demonstrações contábeis buscassem maximizar o valor desses ativos para, quem sabe, melhorar uma situação que não se revelasse tão favorável antes do reconhecimento referido.

\subsubsection{Análise do Comportamento do Índice de Retorno sobre o Patrimônio Líquido (RPL)}

Nessa etapa da análise, foram calculados os Índices de Retorno sobre o PL, sem e com o reconhecimento de Impostos Diferidos, os quais impactam no PL das empresas, aumentando ou diminuindo o lucro. 
Para se efetuar a análise, quando se retirou os Impostos Diferidos do resultado, o Patrimônio Líquido foi também ajustado. Na Tabela 7, é apresentada a estatística descritiva desses dados.

Tabela 7 - Índices de Retorno sobre o PL sem e com o reconhecimento de AFDs

\begin{tabular}{ccccccccc}
\hline Índices & ANO & Média & Desvio Padrão & Variância & $\mathbf{1}^{\mathbf{0}}$ Quartil & Mediana & $\mathbf{3}^{\mathbf{0}}$ Quartil & $\mathbf{n}$ \\
\hline \multirow{3}{*}{ RPL Sem AFDs } & $\mathbf{2 0 0 6}$ & 0,2058 & 0,3649 & 0,1332 & 0,0426 & 0,1629 & 0,3304 & 34 \\
& $\mathbf{2 0 0 7}$ & 0,09707 & 0,6461 & 0,4175 & 0,03411 & 0,1054 & 0,2481 & 35 \\
& $\mathbf{2 0 0 8}$ & $-1,4262$ & 9,1161 & 83,1031 & 0,0054 & 0,0991 & 0,1831 & 36 \\
\multirow{3}{*}{ RPL Com AFDs } & $\mathbf{2 0 0 6}$ & 0,1394 & 0,1655 & 0,0274 & 0,0000 & 0,1335 & 0,2405 & 34 \\
& $\mathbf{2 0 0 7}$ & 0,0306 & 0,3709 & 0,1376 & 0,0000 & 0,0587 & 0,1573 & 35 \\
& $\mathbf{2 0 0 8}$ & $-1,4327$ & 8,5768 & 73,5613 & $-2,027 e-4$ & 0,0347 & 0,1611 & 36 \\
\hline
\end{tabular}

Fonte: Dados da pesquisa.

Aplicando o Teste "t", conforme dados da Tabela 8, verifica-se, apesar das diferenças de médias registradas na Tabela 7 , que não existe diferença estatisticamente significante entre as médias de RPL sem o reconhecimento de AFDs e com o reconhecimento de AFDs, nos exercícios examinados.

Portanto, entende-se que, em média, o Índice de Retorno sobre o Patrimônio Líquido da amostra não sofre alteração estatisticamente significativa com o reconhecimento de AFDs.

Concluindo essa parte do estudo, observa-se que as análises apresentadas nesta seção revelam que o reconhecimento de AFDs por parte das empresas da amostra trouxe reflexos positivos à sua situação financeira, pois melhorou os seus índices de liquidez e de endividamento.

Tabela 8 - Significância entre a diferença de RPL sem e com o reconhecimento de AFDs

\begin{tabular}{cccc}
\hline Índice & ANO & t-estatístico & P-Valor \\
\hline \multirow{3}{*}{ RPL } & $\mathbf{2 0 0 6}$ & 0,911 & 0,369 \\
& $\mathbf{2 0 0 7}$ & 0,260 & 0,796 \\
& $\mathbf{2 0 0 8}$ & 0,003 & 0,998 \\
\hline
\end{tabular}

Fonte: Dados da pesquisa.

De outra parte, a consideração dos Impostos Diferidos sobre Lucros não se mostra como fator influente no retorno das empresas da amostra, pois as médias do índice de RPL não se revelam estatisticamente diferentes nas análises realizadas. Os resultados obtidos nessas análises oferecem a principal resposta buscada neste estudo.

\subsection{Análise de Correlação entre Índices Financeiros e Econômicos e Índice de Ativos Fiscais Diferidos (IAFD)}

O IAFD revela o quanto os valores relativos a AFDs representam no Ativo Total da empresa, sendo utilizado para examinar se existe relação entre o montante de AFDs no ativo de uma empresa e os índices calculados anteriormente. Esse índice foi utilizado no estudo de Kronbauer e Alves (2008) para verificar se existe relação entre o reconhecimento de AFDs por parte da empresa com os demais índices de situação financeira, econômica e de tamanho

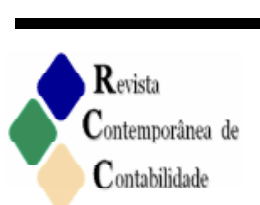


das empresas estudadas. Assim, o IAFD revela-se como um indicador da significância dos ativos fiscais na dimensão do ativo total.

Na sequência, na Tabela 9, apresenta-se a estatística descritiva dos Índices de Ativos Fiscais Diferidos (IAFDs) das empresas estudadas.

Tabela 9 - Estatística Descritiva dos Índices de Ativos Fiscais Diferidos

\begin{tabular}{ccccccccc}
\hline Índices & ANO & Média & Desvio Padrão & Variância & $\mathbf{1}^{\mathbf{0}}$ Quartil & Mediana & $\mathbf{3}^{\mathbf{0}}$ Quartil & $\mathbf{n}$ \\
\hline \multirow{3}{*}{ IAFD } & $\mathbf{2 0 0 6}$ & 0,0309 & 0,0442 & 0,0019 & 0,0045 & 0,0181 & 0,0383 & 34 \\
& $\mathbf{2 0 0 7}$ & 0,0272 & 0,0317 & 0,0010 & 0,0054 & 0,0182 & 0,0358 & 35 \\
& $\mathbf{2 0 0 8}$ & 0,0342 & 0,0332 & 0,0011 & 0,0097 & 0,0204 & 0,0526 & 36 \\
\hline
\end{tabular}

Fonte: Dados da pesquisa.

Para verificar se existe ligação entre o IAFD e os demais índices analisados na seção 4.2 deste estudo, realizou-se análise de correlação. A depender da dimensão da representatividade do IAFD, busca-se compreender se há indícios de que possa haver influência na decisão de contadores e gestores no momento de reconhecer maior ou menor nível de AFDs

Primeiro, efetuou-se o cálculo de correlação entre o IAFD e a LC para verificar se existe alguma relação entre o valor de AFDs no ativo total da empresa com o Índice de Liquidez Corrente, conforme dados da Tabela 10.

Tabela 10 - Correlação entre IAFD e LC com AFDs

\begin{tabular}{ccccc}
\hline ANO & Corr $(\mathbf{r})$ & Erro Padrão & $\mathbf{P}(\mathbf{r}=\mathbf{0})$ & $\mathbf{n}$ \\
\hline $\mathbf{2 0 0 6}$ & $-0,0734$ & 0,1763 & 0,6799 & 34 \\
$\mathbf{2 0 0 7}$ & 0,1449 & 0,1722 & 0,4063 & 35 \\
$\mathbf{2 0 0 8}$ & 0,0924 & 0,1708 & 0,5920 & 36 \\
\hline
\end{tabular}

Fonte: Dados da pesquisa.

Pelos dados da Tabela 10, infere-se que não há correlação entre o IAFD e LC com AFDs em nenhum dos anos estudados, pois " $\mathrm{P}(\mathrm{r}=0)$ " é bastante superior a 0. Portanto, entende-se que o reconhecimento de AFDs nas empresas da amostra não está ligado de forma isolada com o Índice de Liquidez Corrente, ou seja, não se pode deduzir que, quanto menor este índice, maior a tendência para o reconhecimento de Ativos Fiscais Diferidos.

Na sequência, efetuou-se os cálculos de correlação do IAFD com o Índice de Liquidez Geral com AFDs, conforme dados da Tabela 11.

Tabela 11 - Correlação entre IAFD e LG com AFDs

\begin{tabular}{lcccc}
\hline ANO & Corr $(\mathbf{r})$ & Erro Padrão & P(r=0) & n \\
\hline $\mathbf{2 0 0 6}$ & $-0,0331$ & 0,1767 & 0,8524 & 34 \\
$\mathbf{2 0 0 7}$ & 0,2351 & 0,1692 & 0,1740 & 35 \\
$\mathbf{2 0 0 8}$ & 0,3263 & 0,1621 & 0,0521 & 36 \\
\hline
\end{tabular}

Fonte: Dados da pesquisa.

Os cálculos da Tabela 11 revelam que, em 2006, não existe correlação significativa entre os índices. Já no ano de 2007, há uma pequena correlação $(23,5 \%)$, com um nível de confiança de $80 \%$, mas, em2008, não se pode descartar uma correlação entre o IAFD e LG 
com AFDs, pois se nota, com um intervalo de confiança de $90 \%$, que existe uma correlação positiva equivalente a $32,6 \%$ (correlação moderada).

Num intervalo de confiança de $95 \%$, entende-se que não existe correlação estatisticamente significativa em nenhum dos períodos analisados, apesar da situação apresentada no ano de 2008. Presume-se, assim, que o Índice de Liquidez Geral (LG) não pode ser considerado como fator determinante para o reconhecimento de AFDs nessa amostra.

Seguindo o mesmo princípio dos cálculos anteriores, relacionou-se o IAFD com o índice de endividamento com reconhecimento de AFDs, conforme dados da Tabela 12.

Tabela 12 - Correlação entre IAFD e Endividamento (Endto) com AFDs

\begin{tabular}{ccccc}
\hline ANO & Corr $(\mathbf{r})$ & Erro Padrão & P(r=0) & n \\
\hline $\mathbf{2 0 0 6}$ & $-0,1037$ & 0,17582 & 0,5595 & 34 \\
$\mathbf{2 0 0 7}$ & $-0,1439$ & 0,1723 & 0,4095 & 35 \\
$\mathbf{2 0 0 8}$ & 0,0090 & 0,1715 & 0,9584 & 36 \\
\hline
\end{tabular}

Fonte: Dados da pesquisa.

Os dados apresentados na Tabela 12 mostram que não existe correlação estatisticamente significativa entre o IAFD e o índice de Endto com AFDs em nenhum dos exercícios pesquisados. Isso pode ser comprovado pelos baixos índices de correlação e pelos valores de $\mathrm{P}$, que em todos os anos apresenta grande probabilidade de não haver correlação entre essas duas variáveis. Entende-se que, nessa amostra, o índice de endividamento não pode ser considerado como fator determinante para o reconhecimento de AFDs por parte das empresas.

Por fim, ao efetuar os cálculos da correlação entre o índice de Ativos Fiscais Diferidos e o índice de retorno sobre o patrimônio líquido com AFDs, percebeu-se que algumas empresas não possuíam Impostos Diferidos, provocando pequenas diferenças no "n", conforme dados da Tabela 13.

Pelos dados da Tabela 13 é possível observa-se que, nos períodos de 2007 e 2008, não existe, isoladamente, correlação significativa entre o IAFD e RPL, ao passo que, em 2006, existe correlação a um intervalo de confiança de 95\%, mesmo que o coeficiente de correlação seja igual a 0,4407(correlação moderada). Isso revela que, a um intervalo de confiança de $95 \%$, o IAFD e o RPL estão correlacionados em aproximadamente $44 \%$ no ano de 2006 nessa amostra de empresas do Novo Mercado da BM\&FBOVESPA.

Tabela 13 - Correlação IAFD e RPL com AFDs

\begin{tabular}{ccccc}
\hline ANO & Corr $(\mathbf{r})$ & Erro Padrão & P(r=0) & n \\
\hline $\mathbf{2 0 0 6}$ & 0,4407 & 0,1696 & 0,0148 & 30 \\
$\mathbf{2 0 0 7}$ & 0,0469 & 0,1794 & 0,7956 & 33 \\
$\mathbf{2 0 0 8}$ & 0,0822 & 0,1709 & 0,6336 & 36 \\
\hline
\end{tabular}

Fonte: Dados da pesquisa.

Assim como observado na análise anterior, referente aos índices financeiros (LC, LG e ENDTO) e econômicos (RSPL), também aqui na análise de correlação entre esses índices e o relacionado aos Ativos Fiscais Diferidos (IAFD), observa-se que não é possível correlacionálo como um fator determinante na ação de reconhecimento dos AFDs. Essa é a resposta à questão complementar analisada pela pesquisa.

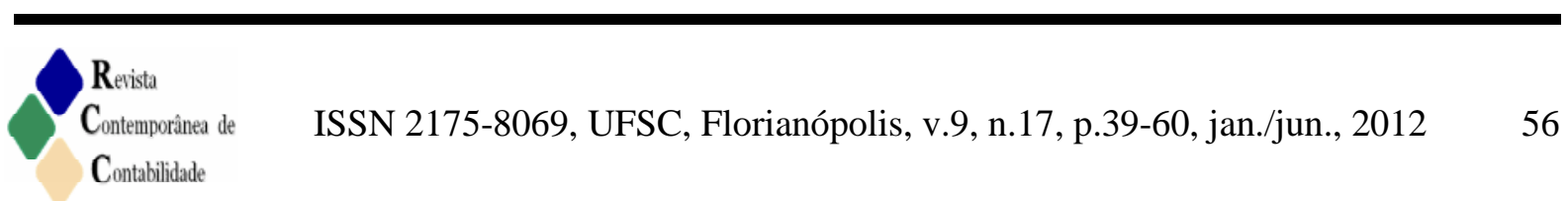


Mesmo assim, os achados deste estudo acabam por reforçar resultados de estudos anteriores, pois, como visto, os Ativos Fiscais Diferidos se mostraram relevantes no que concerne ao aumento dos índices de liquidez e à diminuição de índices de endividamento o que ensejaria o uso das margens facilitadas pelas normas contábeis para reconhecer maiores valores de AFDs quando isso beneficia a empresa em sua situação financeira.

\section{Conclusão}

No estudo realizado, observou-se que os índices de liquidez corrente, liquidez geral e endividamento das empresas analisadas sofrem alterações significativas e favoráveis com o reconhecimento dos Ativos Fiscais Diferidos. Observa-se, assim, aumento dos índices de liquidez e redução do índice de endividamento.

Os índices de Retorno sobre o Patrimônio Líquido são afetados de forma contrária aos demais. De fato, com o reconhecimento de Impostos Diferidos sobre o Lucro (ID), os índices de retorno diminuem, fazendo com que as empresas apresentem um lucro menor e, por conseguinte, menor retorno sobre o seu patrimônio líquido. Contudo, essa diferença não é estatisticamente significante.

Sabendo que as diferenças entre os índices financeiros de Liquidez e Endividamento, são estatisticamente significantes, foram utilizadas variáveis anteriormente analisadas por Kronbauer e Alves (2008) para tentar explicar se algum dos índices econômico-financeiros é determinante para o reconhecimento de AFDs por parte das empresas da amostra. Nesse sentido, foram realizados os cálculos de correlações de cada um dos índices com o IAFD, obtendo-se um resultado que não aponta correlação estatisticamente significativa entre eles. Entretanto, o índice de Retorno sobre o Patrimônio Líquido apresenta correlação significativa apenas no ano de 2006.

Os resultados obtidos na presente investigação não invalidam estudos anteriores que apresentaram resultados não confirmados na presente pesquisa, pois se trata de estudos realizados em amostras distintas, em períodos distintos. Mesmo que em estudos anteriores os índices de liquidez e endividamento tenham sido fatores significativos em relação ao nível de reconhecimento de AFDs (correlação), essa mesma relação não se confirmou na presente pesquisa. Mesmo assim, neste estudo confirmaram-se premissas de estudos anteriores, ou seja, o reconhecimento de Ativos Fiscais Diferidos afeta positivamente os índices de liquidez e endividamento das empresas.

A necessidade de transparência e conformidade exigida das empresas que compõem o Novo Mercado da BM\&FBOVESPA pode ser um fator que explique a não existência de correlação entre o IAFD e as variáveis correlacionadas. Isso de certa forma afasta a existência da adoção oportunista de normas contábeis no momento de reconhecer maior ou menor nível de Ativos Fiscais Diferidos (AFDs). Mesmo que o reconhecimento dos referidos ativos tenha se mostrado um fator que contribui para melhorar os índices de liquidez e endividamento das empresas, não há indícios estatisticamente significativos de que o reconhecimento de AFDs tenha ocorrido de forma deliberada para causar tal melhora nos índices referidos.

Dada a amplitude dessa linha de pesquisa, outros estudos poderão ainda ser desenvolvidos, a saber: (a) Estudar o impacto do reconhecimento de Ativos Fiscais Diferidos nas empresas que fazem parte dos níveis 1 e 2 de governança corporativa da BM\&FBOVESPA, ou mesmo, ampliar as análises por segmentos de atividades 
econômicas; (b) Comparar o nível de reconhecimento de Ativos Fiscais Diferidos entre as empresas da BM\&FBOVESPA e das principais bolsas de valores de norte-americanas e europeias; (c) Ampliar o escopo de estudos analisando o impacto e fatores relacionados ao reconhecimento de Passivos Fiscais Diferidos, bem como de outras variáveis explicativas.

\section{Referências}

ANDERSON, David R.; SWEENEY, Dennis J.; WILLIAMS, Thomas A. Estatística aplicada à administração e economia. 2. ed. São Paulo: Thomson, 2003.

BOVESPA - BOLSA DE VALORES DE SÃO PAULO. Regulamento de listagem do Novo Mercado. Disponível em: <http://www.bovespa.com.br/pdf/RegulamentoNMercado.pdf>. Acesso em: 15 maio 2009.

CFC - CONSELHO FEDERAL DE CONTABILIDADE. Resolução CFC n. 998/2004 - NBC T 19.2 - Tributos Sobre Lucros, Brasília, 2004. Disponível em: http://www.cfc.org.br. Acesso em: 3 jun. 2008.

CPC - COMITÊ DE PRONUNCIAMENTOS CONTÁBEIS. Pronunciamento de n. 32: Tributos sobre o Lucro. Disponível em: http://www.cpc.org.br. Acesso em: 3 abr. 2012.

CVM - COMISSÃO DE VALORES MOBILIÁRIOS. Deliberação CVM N. 273/1998. Brasília, 1998, Disponível em: http://www.cvm.gov.br/. Acesso em: 02 jun. 2008.

CVM - COMISSÃO DE VALORES MOBILIÁRIOS. Instrução CVM N. 371/2002. Brasília, 2002. Disponível em: http://www.cvm.gov.br/. Acesso em: 2 jun. 2008.

CVM - COMISSÃO DE VALORES MOBILIÁRIOS. Deliberação CVM N. 539/2008. Brasília, 2008. Disponível em: http://www.cvm.gov.br/. Acesso em: 2 jun. 2008.

DANTAS, José A.; ZENDERSKY, Humberto C.; SANTOS, Sérgio C.; NIYAMA, Jorge K. A dualidade entre os benefícios do disclosure e a relutância das organizações em aumentar o grau de evidenciação. Economia e Gestão da PUC Minas, v. 5, n. 11, p. 56-76, dez. 2005.

DELOITTE. Normas internacionais de Contabilidade IFRS. São Paulo: Atlas, 2006.

FABRETTI, Láudio C. Contabilidade tributária. 10 ed. São Paulo: Atlas, 2006.

FERNÁNDEZ R., Elena; MARTÍNES A., Antonio; ÁlVAREZ G., Santiago. Contabilidad versus fiscalidad: situación actual y perspectivas de futuro en el Marco Del Libro Blanco de la Contabilidad. Inst. de Estudios Fiscales. Universidad Complutense de Madrid. DOC, $\mathrm{n}^{\circ}$ 02/03, 2003.

GARCÍA-AYUSO C., Manuel; ZAMORA R., Constancio. Análisis de los factores determinantes en el reconocimiento de créditos por pérdidas fiscales en las empresas españolas. Revista Española de Financiación y Contabilidad, v. XXXII, n. 117, p. 395-429, Abril-Junho 2003.

GONÇALVES, Odair; OTT, Ernani. A evidenciação nas companhias brasileiras de capital aberto. In: ENCONTRO NACIONAL DOS PROGRAMAS DE PÓS-GRADUAÇÃO EM ADMINISTRAÇÃO - EnANPAD, 26, 2002. Anais... Salvador: ANPAD, 2002. 
GORDON, E. A.; JOOS, P. R. Unrecognized deferred taxes: evidence from the U. K. The Accounting Review, v. 79, n. 1, p. 97-124, January 2004.

HENDRIKSEN, E. S.; VAN BREDA, M. F. Teoria da Contabilidade. São Paulo: Atlas, 1999.

IASB - INTERNATIONAL ACCOUNTING STANDARDS BOARD. NIC 12, Impostos sobre o lucro. Disponível em: <http://www.iasb.org/NR/rdonlyres/F871ED17-E471-42D0-82465A80D1DBF940/0/PTSummary_IAS12_pretranslation_LA.pdf >. Acesso em: 2 ago. 2008.

IBGC - INSTITUTO BRASILEIRO DE GOVERNANÇA CORPORATIVA. Código das melhores práticas de governança corporativa. Disponível em: http://www.ibgc.org.br. Acesso em: $1^{\circ}$ jun. 2009.

IBRACON - INSTITUTO DOS AUDITORES INDEPENDENTES DO BRASIL. Contabilização do Imposto de Renda e da contribuição social. NPC IBRACON 25/98. Disponível em: <http://www.ibracon.com.br>. Acesso em: 27 fev. 2009.

IUDÍCIBUS, Sergio; MARTINS, Eliseu; GELBCKE, Ernesto R.; SANTOS, Ariovaldo dos. Manual de Contabilidade societária: aplicável a todas as sociedades. São Paulo: Atlas, 2010.

KRONBAUER, Clóvis A.; MORENO R., José. Tratamento contábil dos tributos sobre o lucro: um estudo comparativo entre as normas brasileiras da CVM e do CFC e a norma internacional de Contabilidade $n^{\circ} 12$ do IASB. In: CONVENÇÃO DE CONTABILIDADE DO RIO GRANDE DO SUL, 10. 2008. Anais... Bento Gonçalves, CRC-SP, 2005.

KRONBAUER, Clóvis A. Información relativa al impuesto sobre beneficios: análisis empírico sobre la divulgación realizada por las empresas del IBEX-35 y del IBOVESPA en los ejercicios de 2003/2005. Tese (Doutorado em Contabilidade e Auditoria). Departamento de Contabilidade e Economia. Universidade de Sevilla. Sevilha, 2008.

KRONBAUER, Clóvis A.; ALVES, Tiago W. Fatores determinantes no reconhecimento de Ativos Fiscais Diferidos numa amostra de empresas do IBOVESPA no período de 2003/2005. In: ENCONTRO DA ASSOCIAÇÃO NACIONAL DE PÓS-GRADUAÇÃO E PESQUISA EM ADMINISTRAÇÃO, EnANPAD, 32, 2008. Anais... ANPAD. Rio de Janeiro, 2008.

KRONBAUER, Clóvis A.; SOUZA, Marcos A.; ALVES, Tiago W.; MORENO R. J. Fatores determinantes do reconhecimento de ativos fiscais diferidos. Revista Universo Contábil, v. 6, n. 4, p. 68-88, out./dez., 2010.

MORENO R. J.; LOPES H., D.; KRONBAUER, C.A.; SOUZA, M.A. La activación de las diferencias temporales positivas en empresas cotizadas españolas: un estudio empírico. Revista Contabilidade, Gestão e Governança, Brasília, v. 13, n. 1, p. 3-15, jan./abr., 2010.

OLIVEIRA, Luís M.; CHIEREGATO, Renato; PEREZ JÚNIOR, José H.; GOMES, Marliete B. Manual de Contabilidade tributária. São Paulo: Atlas, 2003.

OLIVEIRA, V. A.; LEMES, S.; ALMEIDA, L. C. F. Gerenciamento de resultados contábeis por meio de ativos fiscais diferidos. Revista UnB Contábil, v. 11, n. 1-2, p.153-169, jan./dez. 2008.

PEREIRA, Ana Beatriz Z. B. T. Tributos diferidos: uma comparação entre normas nacionais e internacionais aplicada a uma amostra de empresas. Dissertação (Mestrado em Administração). Faculdade de Estudos Administrativos - FEAD. Belo Horizonte, 2007. 
PRICEWATERHOUSECOOPERS. Contabilidade no contexto internacional. CRC-SP. São Paulo: Atlas, 1997.

WASSERMAN, Claudio. O ativo fiscal diferido no sistema financeiro nacional: análise e proposta de contabilização. Dissertação (Mestrado Ciências Contábeis), Universidade de São Paulo - FEA/USP, 2004. 